\title{
PESQUISA QUALITATIVA EM EDUCAÇÃO: APORTES TEÓRICOS
}

\author{
Ana Tereza de Oliveira ${ }^{1}$
}

\section{Resumo}

No contexto atual, a pesquisa qualitativa tem adquirido maior relevância para o estudo das relações sociais. Os novos contextos e perspectivas sociais apresentam as particularidades local e temporal de situações específicas, onde as expressões e atividades humanas clamam por reconhecimento. Nesse sentido, o presente artigo se propõe a discutir a relevância da abordagem qualitativa, em especial, a constituição da comunidade cientifica no âmbito social, o papel do pesquisador e os aspectos que caracterizam a pesquisa em educação. Por fim, conclui-se que a produção do conhecimento científico se pauta tanto em exigências de qualidade formal quanto política. Tal assertiva é necessária para o entendimento da ciência como ato político em sentido amplo, comprometida com a criação de novas possibilidades de mudança da realidade, através da produção de novas práticas e de novas formas de conceber o mundo.

Palavras-Chave: Pesquisa em educação. Abordagem qualitativa. Pesquisador.

\section{Introdução}

As ciências humanas, concebidas no cenário da racionalidade moderna, têm suas bases pautadas nos critérios e modelos originados das ciências físico matemáticas. Nesse sentido, o desenvolvimento de uma epistemologia crítica só se tornou possível devido à distância estabelecida em relação a tal modelo. Era necessário esclarecer e especificar a dimensão propriamente humana da atividade epistemológica, sendo que a compreensão aparece como foco intencional ao contrário do ato de explicar. A compreensão é própria do comportamento humano, estando sempre implicada com o singular, com a subjetividade.

Assim, a compreensão da atividade científica requer o reconhecimento da relação entre o fazer científico e as bases políticas, históricas, econômicas e culturais que sustentam os grupos que realizam estudos. O fazer científico institui uma maneira específica de conceber o mundo. Tal abordagem nos instiga a considerar o caráter histórico das práticas científicas, questionando portanto a

1 Graduada em Pedagogia pela Universidade do Estado da Bahia/UNEB. Coordenadora Pedagógica do Colégio Municipal Eraldo Tinoco. E-mail: anat-85@hotmail.com 
sua "a-historicidade", a sua universalidade, a sua absolutez, o seu caráter quase sagrado (Fourez,1995). Sobre o caráter histórico e social da ciência, é interessante observar que a ciência bem como outras formas de conhecimento figuram como construções humanas ancoradas em tempos e lugares específicos.

O desenvolvimento do conhecimento científico está atrelado à necessidade de romper com a visão espontânea, ancorada nos fatos mundanos da vida cotidiana. A ciência bem como a arte ou as técnicas figuram como construções humanas datadas e localizadas numa determinada sociedade. Nesse sentido, é possível afirmar que os constructos teóricos instituídos comunicam a forma como percebemos o mundo e que a recusa ou adoção de um determinado modelo não se baseia unicamente em critérios abstratos e gerais, mas também se apoiam em fatores econômicos, interpessoais, políticos, culturais, afetivos, entre outros (FOUREZ,1995).

A rápida disseminação das pesquisas qualitativas dentro de um campo dominado por uma outra maneira de fazer ciência provoca um confronto entre os paradigmas positivista e interpretativista, pois os adeptos do paradigma positivista instituído afirmam que as pesquisas qualitativas realizadas sob 0 princípio do que se convencionou chamar paradigma construtivista/interpretativo não passam de uma versão menos fidedigna da qual são feitos os bons estudos quantitativos. Para Darlaston-Jones (2007) a ciência, em especial a Psicologia, não compreende que os pressupostos instituídos como cânone ao longo da história da humanidade, estão ancorados numa determinada concepção de mundo, constituindo-se uma epistemologia.

Outro aspecto fundamental que marca a transição de uma epistemologia ancorada na passividade do sujeito para uma epistemologia que concebe a emancipação é a necessidade de dar voz ao participante, uma vez que a interpretação da cultura não deve partir apenas de um único olhar, sobretudo aquele ao qual o estatuto da ciência confere maior autoridade. Esse paradigma vai além da abordagem observacional, uma vez que reconhece a multiplicidade das vozes dos sujeitos como importantes para compreender a cultura. 
No tocante às acaloradas discussões acerca dos sentidos atribuídos ao binômio qualitativo versus quantitativo, Flick (2004) informa que a metodologia qualitativa, muitas vezes, é utilizada como complementar ao método quantitativo, numa perspectiva que considera aquele tipo de método menos legítimo e que precisa de confirmações fundamentais em técnicas quantitativas. Em outro sentido os dois tipos de metodologia podem ser combinados e integrados sem que se comprometa a qualidade e a legitimidade da pesquisa.

Todavia, os problemas em relação à integração dos dois métodos não foram completamente solucionados. Incorre-se ainda, na prática de se utilizar uma abordagem depois da outra, ou utilizá-la paralelamente em graus diferenciados de relevância e preferência ou em situações em que uma é sobreposta à outra. Assim, é possível aliar as duas abordagens em uma pesquisa de modo a aprofundar o conhecimento que se quer obter de um determinado objeto de estudo.

Em virtude dos limites do presente artigo, serão discutidos aspectos relacionados à relevância da abordagem qualitativa, em especial, a constituição da comunidade cientifica no âmbito social, o papel do pesquisador e os aspectos que caracterizam a pesquisa em educação.

\section{Pesquisa educacional: reflexões iniciais}

Com a emergência da pluralização das esferas de vida, a pesquisa qualitativa tem adquirido maior relevância para o estudo das relações sociais. Os novos contextos e perspectivas sociais apresentam as particularidades local e temporal de situações específicas, onde as expressões e atividades humanas clamam por reconhecimento. Nesse momento, não apenas as questões abstratas e universais chamam a atenção dos pesquisadores, mas, sobretudo, aquelas concernentes às experiências sociais e biográficas dos sujeitos, bem como as tradições e formas de vida locais existentes (FLICK, 2004).

Essa nova configuração traz desafios para os procedimentos teóricometodológicos a serem adotados nas pesquisas, uma vez que os estudos quantitativos já não dão conta de compreender esses processos. Daí que a 
pesquisa empírica requer uma nova sensibilidade. A abordagem qualitativa considera a existência de uma multiplicidade de métodos, o estudo do uso e a coleta de uma diversidade de materiais empíricos que apresentem situações e sentidos concernentes à vida diária dos indivíduos. A utilização de diversas práticas interpretativas objetiva compreender de forma mais consistente 0 assunto estudado (DENZIN E LINCOLN, 2006).

Ao demonstrar preocupação com as questões epistemológicas que devem perpassar a produção científica na área educacional, Gamboa (2007) conclama à reflexão tanto os pesquisadores dos programas de pós graduação em educação como os pesquisadores seniores que estabelecem vínculo e compromisso com a realidade educacional.

Destaca ainda que a produção científica, na área educacional, centra-se em aspectos referentes às técnicas e metodologias, em detrimento da discussão sobre o método e as epistemologias, tratadas ainda em enfoque positivista. Vale lembrar que o cultivo à neutralidade, ao distanciamento no processo de conhecer, o fechamento nas certezas construídas pela inflexível objetividade, situam o positivismo sob a égide do autoritarismo, que ao desconsiderar as bases constitutivas de outras formas de conceber o mundo, legitima-se como verdade absoluta.

No que tange à utilização de técnicas e métodos qualitativos de pesquisa nas ciências humanas e sociais, especialmente na área de educação, BortoniRicardo (2008) recupera o debate entre as abordagens positivista e interpretativista, haja vista que muitos pesquisadores qualitativistas resistem em aceitar um modelo único de pesquisa para todas as ciências.

Gamboa (2007) e Gatti (2007) destacam que a pesquisa em educação se reveste de características específicas, mas ainda apresenta dificuldades de construir na área categorias teóricas mais consistentes, constituindo-se como um campo epistemológico em construção. A análise de diversos trabalhos aponta a ausência da apresentação do percurso epistemológico do pesquisador no itinerário da pesquisa, a permanência do imediatismo quanto à escolha dos problemas de pesquisa, a utilização indiscriminada e individualizada dos 
instrumentos e o desconhecimento dos pesquisadores sobre os princípios básicos dos métodos.

Sobre esse aspecto, vale ressaltar ainda, que estudiosos adeptos dos métodos qualitativos de investigação estavam preocupados em defender a validade e a importância de sua posição metodológica, frente aos adeptos dos métodos quantitativos. Essa preocupação gerou um descuido dos critérios para avaliar as pesquisas dentro de seu próprio paradigma epistemológico. Tais critérios são imprescindíveis e devem fazer parte das preocupações dos pesquisadores qualitativos, afinal os critérios de qualidade para esse tipo de investigação necessitam ser discutidos e explicitados, tanto para a comunidade científica como para a sociedade (FLICK, 2004).

A utilização de dados qualitativos possibilita a apreensão do caráter complexo e multidimensional dos fenômenos em sua manifestação natural, estabelecendo relação com o contexto cultural mais amplo. Para Denzin e Lincoln "a competência da pesquisa qualitativa é, portanto, o mundo da experiência vivida, pois é nele que a crença individual e a ação e a cultura entrecruzam-se" (op. cit., p. 22). É a preocupação com o entendimento dos contextos em que estão inseridos os sujeitos, especialmente as singularidades das ações e interações, que motivam os/as pesquisadores a frequentar os locais de estudo. Essa dimensão interpretativa da pesquisa qualitativa possibilita ao/à pesquisador/a conhecer os significados que os sujeitos atribuem aos fenômenos que marcam sua condição no mundo.

O entendimento da pesquisa como uma atividade sistemática trouxe a figura do pesquisador, como sujeito intelectual, cuja formação deve ser constante, dada a relevância desta para o êxito do trabalho científico. Gondim e Lima (2006) apontam que a formação de um bom pesquisador está associada à prática leitora crítica e reflexiva, uma vez que essa postura possibilita a escrita eficiente das questões e inquietações intelectuais. O processo de produção das ideias requer uma ação de escrita e reescrita eficientes, que seja compreensível para os leitores. 
No que concerne à investigação, as razões que motivam o estudo, bem como a construção do percurso são apontados como relevantes para a realização da pesquisa. Dessa forma, a comunicação do pesquisador com o campo constitui-se em aspecto inerente à produção do conhecimento, sendo que a sua subjetividade e dos sujeitos envolvidos fazem parte do processo de pesquisa.

A curiosidade e a disciplina, a reflexão teórica e o contato direto ou indireto com o mundo empírico, também são primordiais para o êxito desta atividade. $O$ pesquisador deve adotar uma postura apropriada, estando atento às consequências da posição assumida para o desenvolvimento da pesquisa, para não incorrer em afirmações equivocadas.

Ao reconhecer o significado dos sujeitos, bem como de seus relatos, também é importante considerar que o pesquisador é alguém que vive, sente e cria. É alguém que atua no mundo, se relaciona e se transforma. Por isso, em todos os momentos, deve haver um esforço do pesquisador em tomar consciência da sua subjetividade, bem como do processo de orientação que rege a sua produção de ideias.

No entanto, é importante destacar que embora a postura adotada pelo pesquisador contribua para o êxito da pesquisa, nem todos os fenômenos importantes para o estudo podem ser observados nas situações em que eles acontecem. O conhecimento do pesquisador apoia-se na observação parcial das ações. Daí a importância de integrar outros métodos de pesquisa que garantam a enunciação verbal como elemento importante para compreender relações e fatos. Para isso, o pesquisador deve ter a oportunidade de experienciar a utilização de novas metodologias, haja vista que o cenário atual conclama uma revisão dos estudos desenvolvidos, sobretudo na área educacional.

Outra dimensão a ser considerada é o processo de análise que desconsidera a voz ou a presença do participante na pesquisa e no relato final do trabalho. O lugar da experiência dos sujeitos deve ser reconhecido como aspecto primordial para a emancipação. O pesquisador não deve apenas falar sobre o pesquisado e sim com ele. 
Ainda sobre o processo de análise, vale destacar que os pesquisadores apresentam dificuldades, em comunicar a forma pela qual alcançaram os resultados, fato que frequentemente oculta o estado nebuloso de realização dessa etapa, que pode ter sido marcada, por exemplo, pelo uso de criatividade e de procedimentos analíticos não hegemônicos.

Em relação a essa dificuldade, Kincheloe e Berry (2007) apontam para a existência de histórias de conflito envolvidas nas decisões tomadas em todo o processo de pesquisa. Esses pesquisadores acreditam que tais conflitos não devem constranger o pesquisador, mas, ao contrário, devem ser documentados "como testemunho da complexidade do trabalho com o conhecimento" (p.63). Tal assertiva destaca 0 aspecto formativo da bricolagem - possibilita 0 aprendizado para o enfrentamento de situações conflitantes e complexas.

Nesse aspecto, Kincheloe e Berry (2007) trazem contribuições importantes para o redimensionamento de práticas engessadas de produção do conhecimento, ainda presentes no meio acadêmico, ao destacar 0 perspectivismo, aporte dos pesquisadores bricoleurs, ressaltando que "ao contrário do empirismo radical do positivismo, o perspectivismo nega que algo pode ser conhecido de forma completa e final" (p. 112). Tal compreensão nos desafia a reconhecer a impossibilidade de abarcar todos os fatos constitutivos do objeto.

A produção de conhecimentos, para ser eficaz, necessita considerar a qualidade formal, já que sua ausência pode acarretar um esvaziamento do seu potencial transformador. A qualidade formal e o avanço do conhecimento científico consideram relevantes, aspectos como a avaliação constante e a comunicação da produção científica.

Outra característica necessária ao pesquisador, diz respeito à capacidade do mesmo em reconhecer as limitações de sua produção bem como a disposição para investir em sua carreira intelectual, fazendo contatos, trocando ideias e socializando a pesquisa, tanto em espaços acadêmicos como nos espaços sociais (Gondim; Lima, 2006). Tal prática é necessária para o enriquecimento do trabalho, uma vez que o expõe às apreciações construtivas dos pares, especialmente quando preservadas as atitudes de confiança, honestidade e reciprocidade. 
O processo de comunicação da produção científica exige dos pesquisadores a tomada de posição frente às questões postas pela sociedade, além de estar atrelada à constituição de espaços, organizados sob o princípio do diálogo, da crítica e da comunicação em rede. Por fim, aspectos como os procedimentos da pesquisa, as razões do estudo, o processo de coleta e análise dos dados, a definição do objeto de pesquisa, bem como a preservação da identidade dos participantes figuram como fundamentais para a respeitabilidade da pesquisa no meio científico. Vale lembrar que a inserção do pesquisador no campo e o acesso às pessoas constitui-se como ação que deve ser cuidadosamente planejada para que se compreenda os aspectos essenciais das questões de pesquisa.

Também a ética que perpassa a construção do trabalho cientifico, vai além das exigências de um código de conduta. Afinal, aspectos como os procedimentos da pesquisa, as razões do estudo, bem como a preservação da identidade dos participantes figuram como fundamentais para a respeitabilidade da pesquisa no meio científico. No que concerne ao debate ético, Fourez (1995) chama a atenção para os processos que mobilizam uma reflexão ética particular, destacando que as experiências de sofrimento humano desencadeiam debates motivados pela indignação e desejo de encontro com a alteridade.

Para a articulação do debate ético, as vozes proféticas são imprescindíveis, especialmente por interrogar sobre as perspectivas de construção da organização social, a partir da problematização do mundo que está posto. É preciso destacar que estas abordagens comunicam o consenso de uma época e de uma cultura, mas são influenciados por outros fatores, para além dos valores éticos. Assim, as lutas ideológicas, bem como os interesses que as sustentam, permeiam o debate ético. Este debate se organiza de uma forma específica, compatível com os objetivos do grupo.

O caráter histórico da ética favorece o entendimento da diversidade como elemento que perpassa as escolhas dos indivíduos ou grupos, no decorrer dos tempos. Isso possibilita pensar sobre as decisões que tomamos e as conseqüências advindas, sobretudo no que se refere ao futuro. Trata-se de reconhecer que nossas ações além de serem marcadas por uma dimensão ética, podem modificar de maneira positiva a própria existência, a dos outros e do 
mundo. As ações marcam a existência humana, constroem o futuro, atribuindo ao homem a condição de sujeito histórico.

\section{A pesquisa e a comunidade científica}

O questionamento acerca da representação dominante da ciência está sustentado nos limites que esta aponta, uma vez que tanto as observações humanas quanto os modelos adotados ou rejeitados estão inscritos num contexto histórico, político, econômico e afetivo. Tal abordagem nos instiga a considerar o caráter histórico das práticas científicas, questionando portanto a sua "a-historicidade", a sua universalidade, a sua absolutez, o seu caráter quase sagrado (FOUREZ, 2009).

No que tange ao caráter histórico da ciência, é interessante observar que a ciência bem como a arte ou as técnicas figuram como construções humanas datadas e localizadas numa determinada sociedade. $O$ fato de estarmos situados num tempo e lugar marcados por uma complexidade acentuada, pode desencadear expectativas e crenças em relação à universalidade, certeza do conhecimento científico. Daí a importância de conceber a comunidade científica e suas práticas, considerando a existência de outras formas de conhecer e organizar o conhecimento produzido. São maneiras "socialmente reconhecidas de resolver as nossas relações com o mundo" (FOUREZ, 2009, p 92).

A definição e constituição de uma comunidade científica, tem como marca o fato de se caracterizar como grupo social bem definido, onde os membros se reconhecem como integrantes de uma mesma organização. Embora, outros grupos sociais sejam constituídos conforme a existência de interesses em comum por parte dos membros, vale ressaltar que a comunidade científica detém maior reconhecimento, em detrimento de outros conhecimentos, e é socialmente reconhecida tanto no âmbito interno (dentro do próprio grupo) quanto no âmbito externo (em outras esferas sociais).

É importante ressaltar que este reconhecimento encontra sustentação na legitimação conferida ao conhecimento científico, disseminada pelos grupos 
dominantes - detentores de poder e decisão. Este reconhecimento traduz-se em garantias de "apoio econômico, poder social e em prestígio" (FOUREZ, 2009, p. 93).

Os desafios interpostos à existência da comunidade científica transcendem a sua relação com o conhecimento, já que instiga seus membros a assumirem uma posição frente às questões postas pela sociedade. $O$ fato dos membros serem detentores de um saber, garante aos mesmos uma condição privilegiada na sociedade (Fourez, 2009). A produção do conhecimento científico figura como desafio e está atrelada à constituição de espaços, organizados sob o princípio do diálogo, da crítica e da comunicação em rede.

Outro desafio diz respeito à ambigüidade do conceito de comunidade científica, afinal é preciso especificar a quem nos referimos quando nos reportamos a essa comunidade. Trata-se da reflexão acerca do "lugar" que os sujeitos ocupam nesse cenário. Quem está autorizado a pensar? Quem executa? (GIROUX,1997).

Vale destacar que a mera referência à comunidade científica pode invisibilizar os conflitos existentes, em razão das divergências de interesses. Portanto, os interesses da comunidade científica comunicam os interesses de uma corporação, o que sugere compreender que neste espaço existam muitas divergências. A discussão em torno da constituição da comunidade científica, no mundo moderno, propõe a localização destes sujeitos na sociedade pertencentes à classe média, que em geral comungam do mesmo ideário que caracteriza a ordem social existente.

A manutenção de um status científico também está associada à garantia de "aliados". Assim a comunidade científica identifica-se com os interesses dos grupos, ao qual se alia. Isso implica em assumir posturas mais atentas a determinadas questões ou a determinada disciplina. Essa aliança também é movida pelo interesse no financiamento de estudos. Muitos são desenvolvidos para responder aos interesses de institutos, corporações, entre outros.

Como exemplo, tem-se o complexo militar-industrial, que a "militarização" da ciência deve ser refletida, considerando as dimensões histórica e geográfica. 
Fourez (2009) informa ainda que embora uma parte da comunidade científica sinta-se constrangida, com os rumos da pesquisa científica - aliança com os objetivos militares - mantém-se numa postura estável diante da situação.

Um aspecto interessante para pensarmos a constituição da comunidade científica é a influência do local social de origem dos cientistas, na maneira de pensar. Como dependem de poderes sobre os quais não possuem um controle direto (a indústria, os militares e o Estado), criticam anunciando que poderiam fazer melhor. Também tende (a comunidade científica) a se tornar um sistema burocrático, em razão da manutenção da defesa de interesses criados por suas organizações internas, fortalecedoras de poderes, clientelas, entre outros. Como conseqüência observa-se a existência de relações corporativistas, bem como a dificuldade de conceber interesses distintos do seu grupo.

Chamar a atenção para o processo de formação dos cientistas é relevante, porque possibilita entender o contexto acima apresentado. Nas sociedades modernas, a classe média por não deter de poder social, deve assumir-se como executora de tarefas. Tem-se assim uma sociedade organizada sobre o princípio da elaboração dos projetos e da execução dos mesmos. Então, o princípio que rege o trabalho da classe média é a execução, em detrimento da reflexão (Giroux,1997). Nesse sentido, faz-se necessário retomar a discussão sobre a formação crítica dos estudantes de ciência, especialmente $\mathrm{o}$ aspecto que se reporta à finalidade social da ciência e as suas implicações. 


\section{Conclusão}

Dentre todos os desafios instituídos para a pesquisa em educação, destaca-se o reconhecimento da relevância das vozes propositivas dos participantes, uma vez que a interpretação da cultura não deve partir apenas de um único olhar, sobretudo aquele ao qual o estatuto da ciência confere maior autoridade.

Esse paradigma vai além da abordagem observacional, uma vez que concebe a multiplicidade das vozes dos sujeitos como importantes para compreender a cultura. Esse reconhecimento é fundamental para a garantia da transição de uma epistemologia ancorada na passividade do sujeito para uma epistemologia que concebe a emancipação.

Vale lembrar também, que a produção do conhecimento científico se pauta tanto em exigências de qualidade formal quanto política. Tal assertiva é necessária para o entendimento da ciência como ato político em sentido amplo, comprometida com a criação de novas possibilidades de mudança da realidade, através da produção de novas práticas e de novas formas de conceber o mundo.

Nesse sentido, aspectos como clareza sobre o papel da fundamentação filosófica e conhecimento sobre os processos metodológicos figuram como elementos indispensáveis para a qualidade das investigações, tanto no âmbito das ciências físicas e matemáticas, quanto no âmbito das ciências sociais e humanas.

Por fim, é preciso destacar que a atividade científica deve ser desenvolvida, a partir de uma reflexão cuidadosa, disciplinada e sistemática, para que os modismos reducionistas não fragilizem o processo de construção do conhecimento. Isso nos ajuda a dar passos mais sólidos em busca da ressignificação dos estudos, sobretudo na área de educação. 


\section{Referências Bibliográficas}

BORTONI-RICARDO, Stella Maris. O Professor Pesquisador: introdução à pesquisa qualitativa. São Paulo: Parábola Editorial, 2008.

DARLASTON-JONES, Dawn. Making connections: The relationship between epistemology and research methods. The Australian Community Psychologist. Vol 19, № 01, may 2007.

DENZIN, Norman; LINCOLN, Yvonna. Introdução: A disciplina e a prática da pesquisa qualitativa. In: . O planejamento da pesquisa qualitativa: teorias e abordagens. Porto Alegre: Artmed, 2006.

DUSCHL, Richard A., GITOMER, Drew H. Epistemological perspectives on conceptual change: Implications for educational practice. Journal of Research in Science Teaching, Volume 28, Issue 9, p.839 - 858 (1991).

FLICK, Uwe. Uma introdução à pesquisa qualitativa. Porto Alegre: Bookman, 2004.

FOUREZ, Gérard. A construção das Ciências: Introdução à filosofia e à ética das ciências. São Paulo: Ed da Universidade Estadual Paulista, 1995.

GAMBOA, Silvio Sánchez. Pesquisa em Educação: métodos e epistemologias. Chapecó (SC): Argos, 2007.

GATTI, Bernardete Angelina. A construção da pesquisa em educação no Brasil. Brasília: Líber Livro, 2007.

GIROUX, Henry. Os professores como intelectuais: rumo a uma pedagogia crítica da aprendizagem. Porto Alegre: Artes Médicas,1997.

GONDIN, Linda M. P.; LIMA, Jacob Carlos. A pesquisa como artesanato intelectual: considerações sobre método e bom senso. São Carlos (SP): Edufscar, 2006.

KINCHELOE, Joe L; BERRY, Kathleen S. Pesquisa em Educação: conceituando a bricolagem. Porto Alegre: Artmed, 2007. 